\title{
Faktor yang Berhubungan dengan Beban Keluarga dalam Merawat Aktifitas Sehari-Hari pada Lansia
}

\author{
Rizky Erwanto
}

Program Studi S1 IImu Keperawatan Universitas Respati Yogyakarta

JI. Laksda Adisucipto Km. 6,3, Depok, Kab. Sleman, Daerah Istimewa Yogyakarta

Email: rizkyerwanto@ymail.com

\begin{abstract}
Abstrak
Perawatan usia lanjut perlu diperhatikan dengan baik, lansia yang mengalami kesulitan dalam melakukan kegiatan aktivitas sehari-hari di rumah, seperti ke toilet, makan, berpakaian (berdandan), mandi dan berpindah tempat. Permasalahan yang berkaitan dengan lansia menimbulkan ketergantungan pada orang lain. Rasio ketergantungan lansia yang bisa digolongkan dalam penurunan kemandirian. Lansia membutuhkan keluarga dalam merawat aktivitas hidup sehari-hari secara mandiri. Perawatan lansia dapat menimbulkan dampak pada keluarga berupa beban yang terjadi karena lansia memerlukan pendampingan yang terus-menerus. Penelitian bertujuan untuk mengetahui beberapa faktor yang berhubungan dengan beban keluarga dalam merawat lansia dalam melakukan perawatan aktivitas sehari-hari. Desain penelitian menggunakan metode pendekatan cross sectional. Metode pengambilan sampel menggunakan teknik cluster sampling. Sampel yaitu anggota keluarga yang merawat lansia yang berjumlah 98 responden. Penelitian dilakukan pada bulan Juli 2015. Uji bivariat yang digunakan adalah uji chi-square. Berdasarkan analisis antara pengetahuan dengan beban keluarga didapatkan p-value 0,002. Hubungan sosial ekonomi yang meliputi pendidikan, pekerjaan, dan pendapatan dengan beban keluarga, didapatkan p-value pendidikan 0,039, pekerjaan 0,017, dan pendapatan 0,0 . Hubungan antara lama merawat dengan beban lansia didapatkan p-value 0,024. Terdapat hubungan yang signifikan antara pengetahuan keluarga, sosial ekonomi keluarga dan lama merawat lansia dengan beban keluarga dalam merawat lansia. Keluarga hendaknya meningkatkan pengetahuan tentang perawatan aktivitas hidup sehari-hari pada lansia dengan banyak membaca dan mencari tahu tentang perawatan aktivitas hidup sehari-hari pada lansia melalui media massa. Kader harus meningkatkan pengetahuan tentang pengetahuan tentang perawatan aktivitas hidup sehari-hari dengan cara mengikuti pelatihan dan penyuluhan yang diadakan di puskesmas sehingga dalam praktiknya kader mendapat wawasan yang luas perawatan aktivitas hidup sehari-hari pada lansia dan mengajarkan kepada keluarga lansia.
\end{abstract}

Kata Kunci: beban keluarga, aktivitas sehari-hari, lansia

\section{Factors Associated with Family Burden in Daily Activities Care of The Elderly}

\begin{abstract}
Treatment of elderly needs to be considered properly, the elderly who has difficulty in performing daily activities at home, such as toileting, eating, dressing, bathing and transferring. Issues relating to the elderly lead to dependence on others. Elderly dependency ratio can be classified in decreasing independence. Elderly needs family to perform their activities of daily living independently. Caring for the Elderly may have an impact on family in the form of expenses incurred for the elderly require continuous assistance. This research aim was to identify several factors related to the family burden of caring for the elderly in the treatment daily activities. The study design used cross sectional method. The sampling method used cluster sampling technique. Respondents that family members caring for the elderly totaling 98 respondents. The study was conducted in July 2015. Bivariate test used chi-square test. Based on bivariate analysis between knowledge and family expenses 0.002. Socioeconomic relations that includes education, employment, and income with the burden of the family, education was obtained p-value 0.039, 0.017 jobs, and income 0.0 . The relationship between long care for the elderly load was obtained p-value 0.024. There were a significant relationship between the
\end{abstract}


knowledge of the family, economic sosial of the family and long of care for the elderly with the burden of caring for elderly relatives. Families should aim to increase knowledge about the care activities of daily living in the elderly with a lot of reading and find out about the care activities of daily living in the elderly through mass media. Cadres should increase the knowledge about the knowledge of the care activities of daily living by means of training and counseling held in the clinic so in practice cadres received extensive insight maintenance activities of daily living in the elderly and families teach the elderly.

Keywords: burden family, daily activities, elderly

Info Artikel:

Artikel dikirim pada 23 Maret 2016

Artikel diterima pada 22 September 2016

DOI : http://dx.doi.org/10.21927/jnki.2016.4(3).117-122

\section{PENDAHULUAN}

Permasalahan yang berkaitan dengan lansia menimbulkan ketergantungan pada orang lain. Rasio ketergantungan lansia yang bisa digolongkan dalam penurunan kemandirian (1). Angka yang menunjukkan tingkat ketergantungan penduduk tua (60 tahun keatas) pada penduduk usia produktif (15-59 tahun) disebut sebagai rasio ketergantungan penduduk lansia (old dependency ratio) yang merupakan besarnya beban ekonomi yang harus ditanggung penduduk produktif untuk membiayai penduduk lansia. Populasi lansia yang tinggal di rumah cukup banyak yang menyebabkan tuntutan perawatan yang lebih besar. Lansia yang melakukan aktivitas hidup sehari-hari secara mandiri maupun bantuan di perlukan care giver salah satunya yaitu keluarga (2).

Keluarga adalah orang terdekat yang merupakan support system utama bagi lanjut usia dalam hal merawat lansia dan mempertahankan kesehatannya. Keluarga memegang andil yang besar dalam pemberian perawatan lansia dalam melaksanakan aktivitas kehidupan sehari-hari (3). Keluarga memegang peranan penting dalam perawatan usia lanjut. Pekerjaan merawat lansia bukanlah suatu hal yang mudah dilakukan karena membutuhkan pengetahuan, keterampilan, kemauan, pengabdian dan kesabaran (2). Perawatan pada lansia sangat komplek dan memerlukan kesabaran dalam merawat lansia keluarga harus lebih memperhatikan kondisi lansia sehingga memerlukan pengetahuan serta keterampilan dalam menjalankan caring kepada anggota keluarga lansia guna mencegah timbulnya penyakit fisik dan mental menjelang hari tua dengan pemberian fasilitas kesehatan yang memadai (3). Keluarga juga berperan dalam pelayanan kesehatan bagi lansia karena keluarga mempunyai perhatian dan kasih sayang yang dibutuhkan oleh lansia (4). Masalah yang sering dialami keluarga dalam menghadapi perawatan lansia yaitu peran pendampingan, komunikasi, kesibukan keluarga, lingkungan susah untuk dimodifikasi sehingga aman untuk lansia, layanan kesehatan yang jauh atau kurang memadai (5). Lansia memerlukan pendampingan yang terus-menerus sehingga dapat menimbulkan dampak pada keluarga berupa beban yang dihadapi keluarga, dan dampak tersebut dapat menimbulkan burden (1). Hal tersebut sesuai dengan Sales bahwa melakukan perawatan pada lansia dengan penyakit kronis dapat menimbulkan perasaan burden atau strain pada care giver yang dapat memberikan pengaruh pada kualitas hidup keluarga (6).

Berdasarkan hasil studi pendahuluan yang telah dilakukan, diantara 7 anggota keluarga yang merawat lansia (care giver), bahwa sebanyak 4 lansia yang mengalami keterbatasan dalam melakukan aktivitas sehari-hari, sehingga segala aktivitas dibantu oleh keluarga dan 3 lansia tidak mengalami keterbatasan, sehingga mampu melakukan aktivitas secara mandiri. Berdasarkan hasil wawancara terhadap 3 anggota keluarga yang yang merawat lansia mengatakan bahwa lansia sangat tergantung kepada anggota keluarga, lansia tidak bisa ditinggal jauh dari rumah, sehingga keluarga merasa terbebani dalam merawat lansia, sedangkan pada lansia anggota keluarga merasa tidak terbebani dalam merawat lansia karena lansia mampu melakukan aktivitas secara mandiri. Penelitian ini bertujuan untuk mengetahui beberapa faktor yang berhubungan dengan beban keluarga dalam merawat lansia, sehingga diharapkan kualitas hidup lansia mengalami peningkatan. 


\section{BAHAN DAN METODE}

Penelitian ini merupakan penelitian yang bersifat kuantitatif dengan menggunakan rancangan desain penelitian analitik korelasi dengan metode pendekatan cross sectional yaitu mempelajari dinamika korelasi antar faktor-faktor risiko dengan efek, dengan cara pendekatan, observasi atau pengumpulan data sekaligus pada suatu saat (point time approach) dan dilakukan pada satu waktu $(7,8)$. Populasi penelitian yang akan dilakukan adalah keluarga dengan lansia yang berumur 60 tahun ke atas yang berjumlah 129 keluarga yang bertempat tinggal di Dusun Saren Desa Wedomartani, Ngemplak, Sleman, Yogyakarta. Jumlah sampel minimal yang dilakukan penelitian sejumlah 98 responden. Metode pengambilan sampel yang dipakai dalam penelitian yang akan dilakukan dengan menggunakan teknik cluster sampling yaitu pengambilan sampel secara acak sederhana yang dilakukan pada setiap clusteryang ada $(7,8)$.

Penentuan sample frame berdasarkan cluster dengan cara mengurutkan RW yang ada di Dusun Saren Desa Wedomartani sebanyak 4 RW. Kemudian ditentukan jumlah cluster (dusun) yang akan dijadikan sampel dengan cara mengundi dan menentukan responden yang terdapat dalam clusters terpilih berdasarkan kriteria yang telah ditentukan oleh peneliti.

Uji validitas yang digunakan adalah uji validitas konstruk, menggunakan uji korelasi berupa pearson product moment dengan membandingkan $r$ hitung dengan $r$ tabel. Uji validitas pada penelitian ini dilakukan di Dusun Bakungan, Desa Wedomartani karena mempunyai karakteristik populasi yang sama, yang membedakan hanya jumlah populasi dan wilayah desa. Nilai $r$ hitung pada pertanyaan yang valid berkisar $0,363-0,800$. Uji reliabilitas yang digunakan dalam penelitian yaitu menggunakan koefisien alpha atau cronbach's alpha. Berdasarkan hasil uji reliabilitas untuk kuesioner pengetahuan keluarga tentang perawatan aktivitas hidup seharihari pada lansia yaitu 0,829 . Variabel independen dan dependen dalam penelitian ini merupakan data kategorik sehingga dianalisis dengan menggunakan uji statistik chi- square.

\section{HASIL DAN BAHASAN}

Distribusi frekuensi pengetahuan keluarga tentang perawatan aktivitas hidup sehari-hari lansia di Dusun Saren Desa Wedomartani Yogyakarta dibagi menjadi pengetahuan tinggi dan rendah yang disajikan dalam Tabel 1.

Tabel 1. Distribusi Frekuensi Pengetahuan Keluarga Tentang Perawatan Aktivitas Hidup Sehari-Hari Lansia di Dusun Saren Desa Wedomartani Yogyakarta Juli, 2015 (n=98)

\begin{tabular}{lcc}
\hline \multicolumn{1}{c}{ Pengetahuan } & f & \% \\
\hline Tinggi & 47 & 48,0 \\
Rendah & 51 & 52,0 \\
Total & 98 & 100 \\
\hline
\end{tabular}

Sumber: Data Primer Tahun 2015

Berdasarkan Tabel 1 diketahui bahwa tingkat pengetahuan keluarga tentang perawatan aktivitas hidup sehari-hari lansia sebagian besar rendah yaitu 51 responden (52,0\%). Salah satu domain penting terbentuknya tindakan seseorang (overt behavior) adalah pengetahuan (kognitif). Berdasarkan hasil pengalaman dan penelitian bahwa perilaku yang didasari oleh pengetahuan akan lebih baik dari pada tanpa didasari oleh pengetahuan (9). Berdasarkan hasil analisis, pengetahuan keluarga yang rendah akan memengaruhi sikap dan tindakan keluarga dalam merawat aktivitas aktifitas hidup sehari-hari pada lansia.

Distribusi frekuensi beban keluarga dalam merawat lansia di Dusun Saren Desa Wedomartani Yogyakarta dibagi menjadi tidak ada beban, beban ringan, beban sedang, dan beban berat yang disajikan dalam Tabel 2.

Tabel 2. Distribusi Frekuensi Beban Keluarga dalam Merawat Lansia di Dusun Saren Desa Wedomartani Yogyakarta Juli, $2015(n=98)$

\begin{tabular}{lcc}
\hline \multicolumn{1}{c}{ Beban } & $\mathbf{f}$ & $\%$ \\
\hline Tidak ada beban & 48 & 49,0 \\
Beban ringan & 18 & 18,4 \\
Beban sedang & 27 & 27,6 \\
Beban berat & 5 & 5,1 \\
Total & 98 & 100 \\
\hline
\end{tabular}

Sumber: Data Primer Tahun 2015

Berdasarkan Tabel 2 diketahui bahwa sebagian besar dalam kategori tidak ada beban dalam merawat lansia yaitu sebanyak 48 responden $(49,0 \%)$. Namun, apabila dilihat dari beban yang dialami keluarga dalam merawat lansia yaitu sebesar $51 \%$ yang terdiri dari beban ringan, beban sedang, dan beban berat. Beban keluarga 
merupakan tingkat pengalaman distress keluarga sebagai efek dari kondisi anggota keluarga yang mengalami penyakit kronik yang dapat menyebabkan meningkatnya stres emosional dan ekonomi dari keluarga $(10,11)$. Adanya beban keluarga dalam merawat lansia, dapat mengakibatkan kurang optimalnya keluarga dalam melakukan perawatan aktivitas sehari-hari pada lansia sehingga kualitas hidup pada lansia akan terganggu.

Distribusi frekuensi status fungsional lansia di Dusun Saren Desa Wedomartani Yogyakarta dibagi menjadi tergantung dan mandiri yang disajikan dalam Tabel 3.

Tabel 3. Distribusi Status Fungsional Lansia di Dusun Saren Desa Wedomartani, Yogyakarta Juli, 2015 $(n=98)$

\begin{tabular}{lcc}
\hline \multicolumn{1}{c}{ Status Fungsional } & $\mathbf{f}$ & \% \\
\hline Tergantung & 45 & 45,9 \\
Mandiri & 53 & 54,1 \\
Total & 98 & 100 \\
\hline
\end{tabular}

Sumber: Data Primer Tahun 2015

Berdasarkan Tabel 3 diketahui bahwa sebagian besar lansia berada dalam kategori mandiri yaitu sebanyak 53 responden $(54,1 \%)$. Seseorang memiliki kemampuan untuk beraktivitas secara bebas, teratur, memiliki tujuan dan mandiri. Permasalahan yang berkaitan dengan lansia menimbulkan ketergantungan pada orang lain. Rasio ketergantungan lansia yang bisa digolongkan dalam penurunan kemandirian (1). Status fungsional mandiri pada lansia menyebabkan beban keluarga dalam merawat lansia menjadi kecil.
Tabel 4. Hubungan Pengetahuan Keluarga dengan

Beban keluarga dalam Merawat Lansia di Dusun Saren Desa Wedomartani, Sleman Yogyakarta pada Bulan Juli, 2015 ( $n=98)$

\begin{tabular}{|c|c|c|c|c|c|c|c|}
\hline \multirow{3}{*}{$\begin{array}{c}\text { Kategori } \\
\text { Pengetahuan }\end{array}$} & \multicolumn{4}{|c|}{ Beban Keluarga } & \multirow{2}{*}{\multicolumn{2}{|c|}{ Total }} & \multirow{3}{*}{ p-value } \\
\hline & \multicolumn{2}{|c|}{$\begin{array}{c}\text { Tidak Ada } \\
\text { Beban }\end{array}$} & \multicolumn{2}{|c|}{$\begin{array}{c}\text { Ada } \\
\text { Beban }\end{array}$} & & & \\
\hline & $f$ & $\%$ & $f$ & $\%$ & $f$ & $\%$ & \\
\hline Rendah & 8 & 26,7 & 22 & 73,3 & 30 & 100 & 0,002 \\
\hline Sedang & 12 & 44,4 & 15 & 55,6 & 27 & 100 & \\
\hline Tinggi & 28 & 68,3 & 13 & 31,7 & 41 & 100 & \\
\hline Total & 48 & 49,0 & 50 & 51,0 & 98 & 100 & \\
\hline
\end{tabular}

Sumber: Data Primer Tahun 2015

Berdasarkan hasil analisis statistik pada Tabel 4 diperoleh data bahwa nilai $p$-value $=0,002$. Terdapat hubungan yang bermakna antara pengetahuan keluarga dengan beban keluarga dalam merawat lansia di Dusun Saren Desa Wedomartani Sleman Yogyakarta. Hasil penelitian ini didukung oleh Narayani dan Kartinah yang menunjukkan bahwa ada hubungan tingkat pengetahuan keluarga terhadap sikap keluarga dalam pemberian perawatan aktivitas hidup sehari-hari pada lansia (12). Pengetahuan merupakan faktor yang sangat penting dalam terbentuknya perilaku seseorang untuk bertindak sesuai dengan yang diharapkan (13). Perilaku yang baik akan terwujud karena adanya stimulus internal yang adekuat, stimulus tersebut adalah pengetahuan dan tanggapan terhadap masalah yang dihadapi (14).

Sebagai pemberi asuhan informal, keluarga dapat melaksanakan fungsi dalam merawat lansia dengan melibatkan seluruh aspek fisik, psikologis, emosional, sosial, dan finansial. Adanya interaksi keluarga dengan

Tabel 5. Hubungan Sosial Ekonomi dengan Beban Keluarga dalam Merawat Lansia di Dusun Saren Desa Wedomartani, Sleman Yogyakarta pada Bulan Juli, 2015 ( $n=98$ )

\begin{tabular}{|c|c|c|c|c|c|c|c|}
\hline \multirow{3}{*}{$\begin{array}{l}\text { Kategori Sosial } \\
\text { Ekonomi }\end{array}$} & \multicolumn{4}{|c|}{ Beban Keluarga } & \multirow{2}{*}{\multicolumn{2}{|c|}{ Total }} & \multirow{3}{*}{ p-value } \\
\hline & \multicolumn{2}{|c|}{ Tidak Ada Beban } & \multicolumn{2}{|c|}{ Ada Beban } & & & \\
\hline & $f$ & $\%$ & $f$ & $\%$ & $f$ & $\%$ & \\
\hline \multicolumn{8}{|l|}{ Pendidikan } \\
\hline Tinggi & 16 & 37,2 & 27 & 62,8 & 43 & 100 & \multirow{2}{*}{0,039} \\
\hline Rendah & 32 & 58,2 & 23 & 41,8 & 55 & 100 & \\
\hline \multicolumn{8}{|l|}{ Pekerjaan } \\
\hline Tidak Bekerja & 2 & 16,7 & 10 & 83,3 & 12 & 100 & \multirow{2}{*}{0,017} \\
\hline Bekerja & 46 & 53,5 & 40 & 46,5 & 86 & 100 & \\
\hline \multicolumn{8}{|l|}{ Pendapatan } \\
\hline Atas UMR & 36 & 80,0 & 9 & 20,0 & 45 & 100 & \multirow{3}{*}{0,00} \\
\hline Bawah UMR & 12 & 22,6 & 41 & 77,4 & 53 & 100 & \\
\hline Total & 48 & 49,0 & 50 & 51,0 & 98 & 100 & \\
\hline
\end{tabular}

Sumber: Data Primer Tahun 2015 
lansia diharapkan dapat memberikan dampak yang positif $(3,5)$. Menurut Wiyono dkk, tenaga kesehatan perlu mengetahui pengetahuan, pemahaman dan keikutsertaan keluarga dalam memberikan perawatan pada lansia untuk mencapai kualitas hidup lansia yang optimal dan dalam memenuhi aktivitas sehari-hari pada lansia (15). Didukung dengan teori bahwa peran keluarga dalam memberikan perawatan pada lansia di rumah yang memiliki ketergantungan tinggi harus didukung dengan pengetahuan yang baik tentang perawatan lansia (15).

Keluarga yang memiliki persepsi pemberian asuhan kepada lansia merupakan suatu beban atau masalah, maka akan memiliki konsep negatif dalam perannnya memberi asuhan. Sebaliknya, jika keluarga memandang pemberian asuhan kepada lansia merupakan suatu kewajiban, peningkatan kesejahteraan, kebanggaan, atau meningkatkan kepuasan, maka akan memiliki konsep positif keluarga sebagai pemberi asuhan dalam aktivitas hidup sehari-hari lansia (15).

Berdasarkan data statistik pada Tabel 5 diperoleh nilai $p$-value pendidikan sebesar 0,039, pekerjaan 0,017, dan pendapatan 0,00. Ketiga data tersebut memiliki nilai $p$-value kurang dari 0,05 . Hal tersebut berarti terdapat hubungan yang signifikan antara status sosial ekonomi yang meliputi pendidikan, pekerjaan dan pendapatan dengan beban keluarga dalam merawat lansia.

Mubarak mengatakan bahwa faktor-faktor yang dapat memengaruhi pengetahuan seseorang yaitu bisa berasal dari tingkat pendidikan, pekerjaan, umur, minat, pengalaman, kebudayaan lingkungan sekitar dan informasi (16). Baik atau tidaknya pendidikan itu tergantung pada faktor-faktor yang mempengaruhinya seperti faktor tujuan (persepsi terhadap pendidikan), faktor pendidik (peran tenaga pendidik), faktor anak didik (umur, status ekonomi, pengetahuan, motivasi), faktor alat-alat (akses fasilitas/pelayanan pendidikan) dan faktor lingkungan/alam sekitar (dukungan sosial) (17). Menurut WHO, beban objektif merupakan beban keluarga yang berkaitan dengan dampak negatif dari kesehatan fisik anggota keluarga, misalnya: kesulitan dalam finansial, masalah dan pengalaman anggota keluarga, serta terbatasnya hubungan sosial dan aktivitas kerja (18). Menurut Wawan dan Dewi bekerja merupakan kegiatan yang menyita waktu sehingga pekerjaan mempunyai pengaruh terhadap keluarga (14). Kesibukan keluarga mencari kebutuhan hidup sehari-hari terutama karena tugas pekerjaan sehingga perawatan pada lansia sering diabaikan (4). Aktivitas yang dilakukan oleh keluarga di luar rumah seperti bekerja mengakibatkan pemenuhan kebutuhan lansia akan perawatan aktivitas hidup sehari-hari seperti makan, mandi, toileting, kontinen (BAB/BAK), berpindah dan berpakaian kurang terpenuhi (5). Keluarga merupakan support system utama bagi lansia dalam mempertahankan kesehatannya tentunya keluarga harus menjalankan peranannya sebagai keluarga dalam perawatan lansia antara lain adalah menjaga dan merawat lansia, mempertahankan dan meningkatkan status mental, mengantisipasi perubahan keadaan sosial ekonomi, serta memberikan motivasi dan memfasilitasi kebutuhan spiritual bagi lansia (2).

Berdasarkan data statistik pada Tabel 6 dengan menggunakan chi-square, maka diperoleh nilai $p$-value $=0,024$, nilai tersebut lebih kecil dari Alpha ( $\alpha$ $=0,05)$ sehingga dapat disimpulkan bahwa secara statistik ada hubungan yang bermakna antara lama merawat lansia dengan beban keluarga dalam merawat lansia di Dusun Saren Desa Wedomartani Sleman Yogyakarta. Beban keluarga merupakan tingkat pengalaman distress keluarga sebagai efek dari kondisi anggota keluarga yang mengalami penyakit kronik yang dapat menyebabkan meningkatnya stres emosional dan ekonomi dari keluarga (10). Menurut Mohr, beban objektif merupakan beban atau hambatan keluarga yang berhubungan dengan pelaksanaan

Tabel 6. Hubungan Lama Merawat Lansia dengan Beban Keluarga dalam Merawat Lansia di Dusun Saren Desa Wedomartani, Sleman Yogyakarta pada Bulan Juli, $2015(n=98)$

\begin{tabular}{|c|c|c|c|c|c|c|c|}
\hline \multirow{3}{*}{ Lama Merawat } & \multicolumn{4}{|c|}{ Beban Keluarga } & \multirow{2}{*}{\multicolumn{2}{|c|}{ Total }} & \multirow{3}{*}{ p-value } \\
\hline & \multicolumn{2}{|c|}{ Tidak Ada Beban } & \multicolumn{2}{|c|}{ Ada Beban } & & & \\
\hline & $f$ & $\%$ & $f$ & $\%$ & $f$ & $\%$ & \\
\hline$<6$ bulan & 16 & 69,6 & 7 & 30,4 & 23 & 100 & \multirow{3}{*}{0,024} \\
\hline$\geq 6$ bulan & 32 & 42,7 & 43 & 57,3 & 75 & 100 & \\
\hline Total & 48 & 49,0 & 50 & 51,0 & 98 & 100 & \\
\hline
\end{tabular}

Sumber: Data Primer Tahun 2015 
perawatan anggota keluarga yang sakit, di antaranya adalah beban biaya finansial untuk perawatan dan pengobatan, tempat tinggal, makanan, transportasi, keuangan, dan intervensi krisis. Hal ini akan semakin meningkat apabila berlangsung lama (19). Terdapat hubungan korelasi yang positif antara beban keluarga dengan lama merawat lansia dengan beban keluarga. Semakin lama waktu yang dibutuhkan keluarga dalam merawat lansia, maka akan semakin besar terjadinya beban dalam merawat aktifitas sehari-hari pada lansia

\section{SIMPULAN DAN SARAN}

Berdasarkan hasil dan bahasan dapat disimpulkan bahwa ada hubungan yang signifikan antara pengetahuan keluarga dengan beban keluarga dalam merawat lansia. Ada hubungan yang signifikan antara status sosial ekonomi yang meliputi pendidikan, pekerjaan, dan pendapatan dengan beban keluarga dalam merawat. Ada hubungan yang signifikan antara lama merawat lansia dengan beban keluarga dalam merawat lansia di Dusun Saren Wedomartani Sleman Yogyakarta.

Diharapkan pihak puskesmas dapat memotivasi dan memfasilitasi kader kesehatan lansia untuk meningkatkan pengetahuan tentang perawatan aktivitas hidup sehari-hari dengan cara mengikuti pelatihan dan penyuluhan yang diadakan di puskesmas sehingga dalam praktiknya kader mendapat wawasan yang luas perawatan aktivitas hidup sehari-hari pada lansia dan mengajarkan kepada keluarga lansia.

\section{RUJUKAN}

1. Miller CA. Nursing for Wellness in Older Adults: Theory and Practice. 6th ed. Philadelphia: J.B Lippincott Company; 2012.

2. Maryam S, Ekasari F, Rosidawati, Hartini T, Suryati. Asuhan Keperawatan pada Lansia. Jakarta: Trans Info Media; 2010.

3. Potter PA, Perry AG. Fundamental Keperawatan. 4th ed. Jakarta: EGC; 2005.

4. Komnas Lansia. Majalah Lansia. Komisi Nasional Lanjut Usia. Jakarta; 2012.

5. Friedman M, Bowden V, Jones E. Keperawatan Keluarga: Riset, Teori, \& Praktik. Jakarta: EGC; 2010.
6. Sales E. Family Burden and Quality of life. Qual Life Res [Internet]. 2003;12 Suppl 1:33-41. Available from: http://www.ncbi.nlm.nih.gov/ pubmed/12803309.

7. Notoatmodjo S. Metode Penelitian Kesehatan. Jakarta: Rineka Cipta; 2010.

8. Dharma KK. Metodelogi Penelitian Keperawatan: Panduan Melaksanakan dan Menerapkan Hasil Penelitian. Jakarta: Trans Info Media; 2011.

9. Anderson LW, Krathwohl DR. Taxonomy For Learning, Teaching And Assessing. A Revision Of Bloom's Taxonomy Of Educational Objectives. New York: Addison Wesley Longman; 2001.

10. Fontaine KL. Mental Health Nursing. 6th ed. New Jersey: Pearson Education Inc; 2009.

11. Kaakinen JR, Gedaly-Duff V, Coehlo DP, Hanson SMH. Family Health Care Nursing: Theory, Practice And Research. Philadelphia: F. A. Davis Company; 2011.

12. Narayani, Kartinah. Hubungan Tingkat Pengetahuan Keluarga terhadap Sikap Keluarga Dalam Pemenuhan Pemberian Perawatan ADL pada Lansia di Rumah di Desa Tanjungrejo Margoyoso Pati. UMS; 2009.

13. Notoatmodjo S. IImu Perilaku Kesehatan. Jakarta: Rineka Cipta; 2010.

14. Wawan A, Dewi M. Teori dan Pengukuran Pengetahuan Sikap dan Perilaku Manusia. Yogyakarta: Nuha Medika; 2011.

15. Wiyono J, Sahar J, Wiarsih W. Pengalaman Keluarga Merawat Lansia dengan Tingkat Ketergantungan Tinggi di Rumah, Kota Malang, Jawa Timur: Studi Fenomenologi. J Keperawatan Indones. 2008;12(2):76-83.

16. Mubarak IW, Chayatin N, Rozikin, Supradi. Promosi Kesehatan. Sebuah Pengantar Proses Belajar Mengajar dalam Pendidikan. 1st ed. Yogyakarta: Graha IImu; 2007.

17. Ahmadi, Uhbiyati. IImu Pendidikan. Jakarta: Rineka Cipta; 2007.

18. WHO. Investing in Mental Health [Internet]. 2008 [cited 2015 Feb 8]. Available from: www.who.int/ mental_health.

19. Mohr WK. Psychiatric Mental Health Nursing. 6th ed. Philadelphia: Lippincott Wiliiam \& Wilkins; 2006. 